\title{
Tempo e história em James Rosenquist
}

\author{
Annateresa Fabris ${ }^{1}$
}

DOI 10.20396/eha.vi14.3169

A ideia de que a pop art é uma celebração monolítica da cultura de consumo é posta em xeque por Bradford Collins, que lembra que diversos artistas, dentre os quais James Rosenquist, usaram imagens da comunicação de massa para defender movimentos progressistas da década de 1960. O autor lembra que quando John F. Kennedy assume a presidência em janeiro de 1961, o país estava ainda sob a égide do conformismo do segundo pós-guerra. Programas como Father knows best e The adventures of Ozzie and Harriet dominavam a programação televisiva e continuavam a ditar padrões de comportamento para toda a sociedade. De acordo com a programação televisiva, o país era branco, convencional, tranquilo e morava nos bairros residenciais afluentes. Por trás dessa fachada, porém, estavam começando a se formar as forças da mudança, principalmente entre os negros, as mulheres e os homossexuais, descontentes com suas vidas quase sem perspectivas e frustrados com os padrões sociais repressivos. ${ }^{2}$

Abrindo um parêntese na exposição de Collins, é necessário lembrar que seu diagnóstico se aplica a The adventures of Ozzie and Harriet, transmitido entre outubro de 1952 e setembro de 1966, mas não a Father knows best, que sai do ar em maio de 1960. Isso não significa deixar de reconhecer que a primeira série, que recebe no Brasil o título de Papai sabe tudo, baseava-se numa representação idealizada da vida familiar por meio dos dois personagens centrais: um vendedor de seguros simpático e sabichão e a esposa que o ajuda a educar os três filhos. Típica representante dos valores da década de 1950, a série, que estreia em outubro de 1954, não sofre, no entanto, o embate com a nova mentalidade que estava sendo gestada no país, como ocorrerá com The adventures of Ozzie and Harriet. Protagonizado pelo diretor de orquestra Ozzie Nelson, pela esposa Harriet e pelos dois filhos do casal, o sitcom caracterizava-se pelo realismo com que eram abordados os problemas diários de uma típica família norte-americana. A realização não consegue sobreviver ao advento de novos valores e ideais e sua representação idealizada da vida familiar acaba sendo considerada datada, o que gera seu cancelamento.

1 Professora Titular aposentada da Escola de Comunicações e Artes da Universidade de São Paulo.

2 COLLINS, 2012, p. 159. 
Quais eram esses novos valores e ideais? Collins destaca em primeiro lugar a oposição crescente contra a guerra do Vietnã que toma corpo em meados da década de 1960. Iniciado durante o governo de Dwight Eisenhower, o envolvimento dos Estados Unidos na guerra do Vietnã se intensifica nas presidências de John Kennedy, Lyndon Johnson e Richard Nixon, defensor da "paz com honra" e da "vietnamização" do conflito. A população que, num primeiro momento, apoiava a guerra em nome da defesa da liberdade e da democracia, começa a assumir uma atitude crítica diante do número crescente de baixas norte-americanas e da divulgação das atrocidades cometidas pelos militares do país, que incluíam bombardeios indiscriminados, uso de napalm e de outros agentes químicos, criação de "aldeias estratégicas" (campos de concentração, na realidade) e massacres de civis. O movimento antibélico começa a constituir-se em 1963, de maneira tímida, nos campi de algumas universidades. O início dos chamados "bombardeios a tapete" contra o Vietnã do Norte, promovidos pelo governo Johnson desde fevereiro de 1965, provoca demonstrações em Nova York, Minneapolis, Berkeley e outros campi, podendo ser destacada a marcha sobre Washington, organizada pela associação Estudantes para uma Sociedade Democrática, que reúne cerca de 20.000 pessoas em 17 de abril. A convenção do Partido Republicano, sediada em Chicago entre 26 e 29 de agosto de 1968, provoca um protesto na cidade no dia 10, além de ser acompanhada de manifestações no momento em que Nixon é escolhido candidato para a eleição presidencial daquele ano. $\mathrm{O}$ repúdio do conflito e a manifestação da descrença na possibilidade de uma vitória estadunidense atingem o apogeu em 15 de novembro de 1969, quando a Marcha contra a Morte leva a Washington mais de 500.000 pessoas.

O segundo acontecimento destacado por Collins é o interesse pelos direitos femininos, manifestado pelo governo Kennedy, que cria em 14 de dezembro de 1961 a Comissão Presidencial sobre o Status das Mulheres. O relatório final, apresentado em 11 de outubro de 1963, reconhecia a discriminação sofrida pelas mulheres em termos de emprego e recomendava, entre outras medidas, iguais oportunidades e a instituição da licença maternidade remunerada. A frustração com a demora em implementar as medidas sugeridas pela Comissão leva à fundação da Organização Nacional de Mulheres (outubro de 1966). Uma de suas fundadoras, Betty Friedan, havia publicado em 1963 o livro Mística feminina, no qual denunciava o confinamento da mulher ao papel de dona de casa, fonte de frustração e de distúrbios psicológicos, que abarcavam tanto sintomas depressivos quanto a compulsão ao consumo, esteio do chamado "modo de vida americano". Dentre as campanhas empreendidas pela organização destaca-se aquela para convencer as universidades exclusivamente masculinas a admitir mulheres nos cursos de graduação. Para comemorar a abertura da Universi- 
dade Yale à admissão de mulheres (setembro de 1969), um grupo de estudantes e ex-alunos encomenda um monumento a Claes Oldenburg. Este concebe, no mesmo ano, Batom (ascendendo sobre esteiras de caterpilar), em que o objeto fálico inflável "expressa a nova união dos sexos, enquanto sua colocação na plataforma de um tanque celebrava obliquamente o feminismo militante, responsável pela mudança política". Collins, que é o autor dessa análise, detecta outro significado na obra de Oldenburg. Ela seria igualmente uma contribuição ao movimento contrário ao conflito do Vietnã: na qualidade de arma fálica, o monumento encarnava o slogan "Faça amor, não faça guerra". Essa leitura da obra encontraria apoio em sua colocação original: sem a permissão da administração da universidade, ela foi colocada em frente ao monumento dedicado à Primeira Guerra Mundial. ${ }^{3}$

É nesse clima marcado por fortes tensões sociais e políticas que Rosenquist concebe F-111 (1964-1965). Composto de 51 seções, que lidam com os temas da violência militar e da prosperidade da classe média, o gigantesco painel é visto por Julia Blaut ${ }^{4}$ como uma tomada de posição crítica do pintor, que explora nele a coexistência de nacionalismo, valores familiares e cultura de consumo, próprios da visão conservadora de uma revista como Life. Para respaldar sua hipótese, a autora propõe uma comparação com o trabalho editorial da revista a partir de um exemplo pontual. Na edição publicada em 15 de julho de 1946, os leitores eram confrontados com duas imagens absolutamente díspares: uma fotorreportagem dedicada a um teste atômico no atol de Bikini ${ }^{5}$ e o reclame de uma garota sorridente chupando um sorvete. Atravessada pela fuselagem de um bombardeiro F-111, a composição caracteriza-se pela justaposição de imagens de diferentes naturezas a essa estrutura básica: um papel de parede com motivos florais, que deveriam sugerir "uma atmosfera pesada e repleta de radioatividade"; uma barreira; um bolo de claras cortado ao meio, símbolo do silo que abrigava os mísseis; um gigantesco pneu para a neve, alusivo ao "complexo militar-industrial", que estava sustentando a guerra do Vietnã; lâmpadas em cores suaves, que evocavam ao mesmo tempo ovos de Páscoa e bombas caindo ${ }^{6}$; uma garota loira e sorridente debaixo de um secador de cabelos, posicionada contra um fundo verde que representava uma grama radioativa; um guarda-sol sobreposto a um cogumelo atômico; um mergulhador; e uma grande massa de espaguetes em molho de tomate, que terminavam em filamentos prateados.

\footnotetext{
3 Ibid., p. 183

4 BLAUT, 2003, p. 19

5 A revista estava divulgando o primeiro teste da Operação Crossroads. Denominado Able, o teste ocorreu em 1 de julho com a detonação da bomba Gilda, assim chamada em homenagem a Rita Hayworth, que interpretava o personagem homônimo no filme dirigido por Charles Vidor (1946).

6 ROSENQUIST, 2009, pp. 160-162.
} 
Aossignificadosjá enunciados pelo artista devem seracrescentados outros para compreender o alcance da composição. A menina debaixo do secador era "uma metáfora do capacete do piloto do jato. A garotinha era de fato o piloto do avião, assim como a classe média era a força viva por trás do avião". Representante da força propulsora do mercado que constrói armas de guerra, ela é "a motivação e a beneficiária desse modo de vida, que garante que todos tenham todas essas coisas - a casa no subúrbio, a TV, a lavadora-secadora, o gramado no quintal". O guarda-sol com o cogumelo atômico e o mergulhador mantêm uma relação estreita entre si. O pintor lembra que um resort de Utah oferecia como atrativo a visão de testes nucleares. As pessoas sentavam debaixo de guarda-sóis para ver "as nuvens em forma de cogumelo no deserto". 7 Nesse contexto, o mergulhador representa "o grande trago de ar consumido por uma explosão nuclear". A metáfora das bolhas está, pois, relacionada com a bomba portadora de morte. Os espaguetes, por fim, remetem à artilharia antiaérea quando vermelhos e à radioatividade quando prateados. ${ }^{8}$

Esse significado complexo e articulado nem sempre é destacado pela crítica. Henry Geldzahler, que detecta na figura do avião "o símbolo do complexo industrial-militar da nossa época, um tema paranoico digno de Dalî", atenua o significado bélico do painel a partir das presenças do bolo, do guarda-sol e da garota sob o secador. A questão do "espectro do surrealismo", que ronda a obra de Rosenquist, é também abordada pelo crítico a partir da ideia de que existe uma diferença fundamental entre a poética francesa e a do pintor norte-americano. Na pintura surrealista os objetos e as imagens existem num espaço que vai além de uma hipotética janela. Herdeiro de Jackson Pollock, Rosenquist pode afirmar que suas imagens são "tão maiores em relação à moldura do quadro que, a princípio, são invisíveis". Sua intenção não é pintar de maneira heroica, e sim produzir "equivalentes visuais da extravagância física de nossa economia, que ele chama 'economia do excesso'". Em vez de ler os elementos visuais transferidos de seu lugar de origem para outro construído pelo artista como uma narrativa, à qual pode ser sobreposta uma moral, Geldzahler prefere pensar que ele transforma o reconhecível em abstração a partir de algumas operações: isolando e ampliando os detalhes até a escala de primeiros planos de Cinemascope e "deslocando o familiar, que coloca num novo contexto". No caso de F-111, essa observação aplica-se particularmente aos espaguetes, que têm como referência tanto a pintura abstrata da década de 1950 quanto o

\footnotetext{
7 Anteriormente, o artista havia conferido um significado um tanto diferente a essa porção da obra. A sobreposição do guarda-sol e do cogumelo atômico poderia evocar a nova visão que alguém teria ao abrir uma janela. Em vez de uma paisagem natural, teria diante de si "uma explosão em vermelho vivo e amarelo" de uma bomba atômica, evocando uma flor de cerejeira. Cf. SWENSON, 1965, p. 599.

8 ROSENQUIST, 2009, pp. 158-160.
} 
cartaz publicitário do qual derivam. ${ }^{9} \mathrm{O}$ primeiro proprietário da obra, Robert C. Scull, considera, ao contrário, que ela é um

comentário sobre o próprio tempo. F-111 faz isso de maneira convincente. Apresenta a essência da relação dos Estados Unidos com o mundo, mostrando a equação da boa vida na paz, com seus luxos e aspirações, e nosso envolvimento com a potencialidade da guerra instantânea e da aniquilação final. Considero o quadro um marco na literatura visual e naquele que é, provavelmente, o maior tema da arte: a luta entre vida e morte. Ele fala com toda a humanidade, empregando a linguagem simples do homem comum, e não os signos secretos do especialista. ${ }^{10}$

Nem todas as fontes visuais utilizadas foram identificadas pela historiografia. Sabe-se que a imagem do secador de cabelos foi derivada de um anúncio da Coca-Cola publicado na última capa da Life de 12 de fevereiro de 1965 e que a dos espaguetes proveio de um reclame da mesma revista divulgado em 18 de setembro de 1950. ${ }^{11}$ A menina, nos dizeres de Rosenquist, era uma modelo infantil. ${ }^{12}$ Uma das colagens preparatórias permite afirmar que sua fonte foi um anúncio publicitário gráfico em preto e branco, que dava a ver uma menina em primeiro plano e um grupo de adultos no fundo, descansando debaixo de um guarda-sol. Michael Lobel propõe duas hipóteses para a fonte do avião: o pintor poderia ter derivado a imagem da imprensa por ocasião do primeiro teste de voo realizado em 21 de dezembro de 1964, ou do press release da General Dynamics, fabricante da aeronave. $\mathrm{O}$ autor dá preferência à segunda hipótese a partir de uma evidência visual: a posição do piloto na cabine divulgada no press release corresponde exatamente à registrada em inúmeras colagens preliminares. ${ }^{13}$ As duas hipóteses podem coexistir, já que Rosenquist lembra ter visto uma foto do avião em fins de 1964 e ter conseguido imagens suplementares logo em seguida. A origem da obra, no entanto, não se esgota nessas fontes impressas. Ao visitar os pais em Dallas, o pintor vira no parque de diversões Six Flags a carcaça enferrujada de um bombardeiro B-36, modelo que não chegou a ser usado e que se tornou rapidamente obsoleto. ${ }^{14} \mathrm{~A}$ pergunta sobre a função do artefato não usado feita naquele momento volta a ecoar em sua mente quando começa a trabalhar no painel. Ao afirmar que o dinheiro investido em "armas de guerra obsoletas" poderia ter sido aplicado em

9 GELDZAHLER, 1968, pp. 280-281

10 SCULL, 1968, p. 283.

11 BLAUT, 2003, p. 38. O anúncio dos espaguetes foi também usado numa obra de 1964, intitulada Campo laranja.

12 ROSENQUIST, 2009 , p. 160.

13 LOBEL, 2009, pp. 126-127.

14 Numa conversa com Alastair Sooke, o artista recorre a outro exemplo: o porta-aviões USS Intrepid, que havia custado "trilhões de dólares" e que estava enferrujando em Manhattan. Cf. SOOKE, 2015, p. 90. Em serviço entre 1943 e 1974, o navio participou da Segunda Guerra Mundial e da Guerra do Vietnã, além de ter sido usado pela agência espacial como navio de resgate. Atualmente é a peça central do Intrepid Sea, Air and Space Museum (Nova York). 
saúde e obras públicas, o artista levanta a questão da responsabilidade ética:

Estávamos pagando impostos para o que parecia ser um avião de combate já obsoleto, para uma máquina de guerra que era esse monstruoso aspirador de taxas. Sob a administração Johnson estávamos sendo submetidos a um aspirador ainda maior: a guerra do Vietnã. ${ }^{15}$

Levando em conta apenas as imagens do avião e do secador, Lobel chega à conclusão de que a obra indica um novo momento na trajetória de Rosenquist: "um compromisso mais resoluto com o presente imediato". ${ }^{16}$ Ao contrário do que o autor afirma, a coexistência de duas temporalidades insere F-111 numa historicidade mais complexa, que cria um enlace com o apogeu do "modo de vida americano" logo depois do término da Segunda Guerra Mundial. Isso fica evidente na relação que Rosenquist estabelece entre a menina, proveniente de um anúncio dos anos 1940-1950, que simboliza a "sociedade de classe média", e uma arma de guerra, que proporciona uma vida confortável aos trabalhadores da indústria aérea, enquanto despeja morte sobre populações inocentes com objetivos nem sempre claros para os norte-americanos. ${ }^{17}$ Essa visão política do significado da obra nem sempre é compartilhada pela crítica. Se Max Kozloff (1968) e Craig Adcock (1991) comparam o painel com o picassiano Cuernica ${ }^{18}$, Hilton Kramer fala de uma obra “lustrosa, alegre, dispersa" que, em termos expressivos, está no mesmo nível da arte comercial, da qual foram derivados os materiais visuais:

Longe de suscitar qualquer emoção profunda sobre o destino da civilização, é o tipo de espetáculo visual -alegre, extrovertido, tecnicamente competente, mas irremediavelmente superficial - que deixa o espectador com a sensação de que deveria estar chupando um picolé. ${ }^{19}$

Escritas por ocasião da apresentação da obra no Museu Metropolitan de Nova York (fevereiro de 1968), ao lado de três quadros de temática histórica, de autoria de Nicolas Poussin (O rapto das sabinas, c. 1637-1638), Jacques Louis David (A morte de Sócrates, 1787) e Emanuel Gottlieb Leutze (Washington cruzando o Delaware, 1851), tais palavras têm um prosseguimento na visão ácida de Sidney Tillim. Se Kramer define a operação do museu como "uma ideia de vulgaridade e

\footnotetext{
15 ROSENQUIST, 2009, pp. 153-154. O artista provou ser um mau profeta. Concebido como uma aeronave de ataque tático, que poderia ser usada também como bombardeiro estratégico nuclear e desempenhar funções de reconhecimento aéreo e de combate eletrônico, o F-111 entrou em serviço em julho de 1967. Foi utilizado pela Força Aérea Norte-Americana até 1996 e pela Real Força Aérea Australiana até 2010.

16 LOBEL, 2009, p. 130.

17 SOOKE, 2015, p. 90.

18 Cf. HANDLER, 1998, p. 91; BLAUT, 2003, p. 39

19 KRAMER, 1997, pp. 253-254.
} 
insensibilidade chocantes" por colocar lado a lado uma obra kitsch (Leutze), dois grandes mestres e o "alto camp" (Rosenquist) ${ }^{20}$, Tillim ${ }^{21}$ também discorda dessa associação por considerar que os quadros históricos não tinham "o significado decorativo e as implicações arquitetônicas" de F-111. Tillim, que não acredita que a pop art tenha condições de produzir murais, não hesita em afirmar que Rosenquist não consegue

corresponder formalmente ao idealismo implícito em seu desejo de uma escala monumental. Seu tema, portanto, sugere a ausência de uma narrativa significativa [...] porque a estrutura que ele utiliza - uma variante do cubismo sintético - impede aqueles valores ilustrativos que são um pré-requisito para a expressão do sentimento. Guernica de Picasso tampouco consegue gerar uma força emotiva pela mesma razão. ${ }^{22}$

Uma das críticas feitas por Tillim - F-111 não era um mural pensado para uma estrutura específica, já que podia ser comercializado em partes $^{23}$ - é retomada por Beth Handler, que Ihe confere outra significação. A venda de painéis individuais permitiria que as pessoas colecionassem "fragmentos de visão", reiterando a experiência criada pelos meios de comunicação de massa que, ao bombardearem visualmente as pessoas, acabam por gerar imagens abstratas. ${ }^{24}$ Tomados individualmente, os painéis assumem uma qualidade abstrata que solapa sua função como partes de um todo, mas seu estilo comercial continua a evocar a linguagem publicitária. A fragmentação formal do painel tem outras implicações para Handler: ao mesmo tempo que enfatiza o interesse do artista pela visão periférica, que é também uma experiência condicionada pelos meios de comunicação de massa, põe em xeque sua possibilidade de "funcionar como uma crítica social e histórica coerente". A conclusão da autora sobre o caráter ambivalente de F-111, que daria a ver, de maneira simultânea, a atração e a crítica exercidas sobre o artista pela paisagem visual do capitalismo e do militarismo ${ }^{25}$, é retomada por Collins. Se este detecta na presença dos espaguetes um "desagradável produto franco-americano: a guerra do Vietnã"26, não deixa de sublinhar a

\footnotetext{
20 Ibid., p. 254.

21 TILLIM, 1997, pp. 261-262.

22 Marcia Tucker acredita que Tillim deturpa o significado do trabalho de Rosenquist, ao pressupor que as imagens "realistas" de uma obra devam ser narrativas, ilustrativas e estilisticamente unificadas de acordo com os princípios da pintura histórica desde David. Segundo esse raciocínio, os artistas não deveriam utilizar nenhum elemento novo para não interromper a continuidade da tradição. Cf. TUCKER, 1972 , p. 28. 23 Adquirido por Robert C. Scull, o painel foi exibido parcialmente na 9a Bienal de São Paulo (1967) no âmbito da seção "Meio natural U.S.A. 1957-1967", apresentada no catálogo por William C. Seitz.

24 Rosenquist havia concebido de fato os painéis como fragmentos de visão incompletos. Eles poderiam ser vendidos isoladamente e ser colecionados como um "registro do tempo ou da história". Leo Castelli, marchand do artista, havia vendido 41 partes do painel quando Robert Scull manifestou a intenção de adquiri-lo integralmente. A transação só foi possível porque Castelli havia incluído uma cláusula nos contratos: as vendas já realizadas poderiam ser canceladas, caso houvesse um comprador interessado em adquirir a obra antes que ela saísse da galeria. Cf. SWENSON, 1965, pp. 596-597; SCULL, 1968, p. 283.

25 HANDLER, 1998, p. 91

26 O autor usa o nome da marca de massas enlatadas mais popular nos Estados Unidos - a Franco-American Spaghetti - para evocar a Guerra
} 
ambivalência de Rosenquist em relação ao material extravagante selecionado e à cultura visual dos Estados Unidos. Apesar de seu conteúdo crítico, o painel "tem um apelo intencionalmente extravagante. As rimas e contrapontos formais, como aquela entre a explosão atômica e as bolhas submarinas, são belos - e o próprio avião também". ${ }^{27}$

Os requisitórios de Kramer e Tillim não levam em conta um fato inequívoco: o de que cada período produz a própria versão de pintura histórica. A versão de O rapto das sabinas de Poussin diz muito mais respeito ao desígnio de evidenciar o próprio conhecimento da escultura antiga, como provam o tratamento dado a gestos e poses e o cuidado em reproduzir uma lorica romana numa das figuras do primeiro plano, do que ao episódio histórico representado. O mesmo raciocínio aplicase à Morte de Sócrates de David, em que a representação do herói estoico se inscreve no esquema neoclássico do contraponto entre a calma com que ele aceita a própria sorte e o desespero dos discípulos. Em Washington cruzando o Delaware, Leutze é guiado pela intenção de retomar a tradição da pintura heroica norte-americana representada por John Singleton Copley, Benjamin West, John Trumbull e Thomas Sully; por isso, capta o espírito do grande líder e a importância do episódio, sem prender-se a detalhes. ${ }^{28}$ Mais próximo em termos estruturais de F-111, por ser concebido de maneira fragmentária, o gigantesco painel Guernica dialoga a um só tempo com a atualidade do episódio que o inspirou, abundantemente reproduzido pela imprensa francesa, e com "experiências, lembranças, obsessões pessoais. Mais profundamente, com o imaginário coletivo" Visões da tauromaquia conjugam-se com fontes provenientes da história da arte (Rafael, Guido Reni, Jean-Dominique Ingres, Pierre-Paul Prud'hon, Anne-Louis Girodet, Auguste Bartholdi) para produzir um "quadro de ideias", destituído de sentimentos épicos e fabulações lendárias, já que responde à nova realidade criada pelo sistema de comunicação de massa. ${ }^{29}$

Totalmente imerso no ambiente gerado pela indústria cultural, Rosenquist define F-111 como uma "reação pessoal [...] às ideias opressivas dos meios de comunicação de massa" e à aceleração promovida pela tecnologia, que estaria destituindo a sociedade dos antigos valores humanos. A relação mais direta com a guerra do Vietnã deveria ser buscada na figura do mergulhador, cuja respiração remeteria a "uma força inatural, criada pelo homem". O pintor lembra que, depois de um bombardeio intenso no Vietnã, que queimou muitos hectares de floresta, formou-se uma

da Indochina (1946-1954), que antecedeu a do Vietnã (1955-1975). O desfecho da primeira pôs fim ao domínio francês, iniciado em 1887, na região.

27 COLLINS, 2012, pp. 193, 198-199.

28 HOWAT, 1968, p. 298

29 FERRIER, 1977, pp. 9, 27, 29. 
tempestade artificial como resultado do calor e da pressão do fogo. A chuva, que ajudou a mitigar o incêndio, foi saudada pelos nativos como um fenômeno natural, mas se tratava de uma "mudança atmosférica criada pelo homem". ${ }^{30}$ Ao lado da garota sob o secador, a figura do mergulhador serve de mote para a análise de Kristin Fedders ${ }^{31}$, baseada na questão dos gêneros. O mergulhador é analisado pela autora a partir de duas referências teóricas: o homem da organização e o homemjato.

Publicado em 1956, o livro The organization man, de William Whyte, apresenta uma visão crítica do conformismo que caracterizava a sociedade norte-americana do segundo pós-guerra. O extraordinário crescimento econômico do país, cujos signos mais visíveis estavam na expansão dos grandes conglomerados, na criação de postos de trabalho para a classe média, numa prosperidade (até certo ponto) generalizada, no incremento da vida em comunidades suburbanas e do uso de tecnologias domésticas, havia gerado um espírito coletivo, que se contrapunha à antiga filosofia individualista e à crença de que o progresso era resultado do trabalho de pessoas talentosas. Baseado em entrevistas com executivos de grandes corporações, entre as quais General Electric e Ford, o livro de Whyte descrevia uma nova situação: a crença no coletivismo levava a delegar a solução dos problemas nacionais às grandes organizações, que incluíam o governo e as forças armadas, cabendo ao indivíduo colocar suas habilidades a serviço dos grupos. ${ }^{32} \mathrm{~A}$ uniformidade desse modo de vida já havia sido flagrada no romance The man in the gray flannel suit (1955), em que Sloan Wilson descrevia a busca de um sentido para a própria vida por parte de Tom Rath num mundo dominado pela mentalidade corporativa. O homem-jato, por sua vez, é apresentado por Roland Barthes como "uma raça nova da aviação, mais próxima do autômato que do herói", cuja mitologia se baseia na "pura cinestesia". Representante da "humanidade-reação", o homem-jato leva uma vida em comum, veste-se de maneira uniforme, sujeita-se a fins coletivos, oferecidos como sacrifício "à singularidade prestigiosa de uma condição inumana". Assimilado pelo próprio nome à pura passividade, o homem-jato recupera, assim mesmo, o ritual por meio do mito de uma raça fictícia, celeste, que realiza "uma espécie de compromisso antropológico entre os humanos e os marcianos". Trata-se de um "herói coisificado, como se, ainda hoje, os homens só pudessem conceber o céu povoado de semiobjetos". ${ }^{33}$

32 O nome de Whyte é citado por Guy Debord na tese 192 de A sociedade do espetáculo (1967), quando o autor faz referência ao "projeto geral do capitalismo desenvolvido que visa ocupar-se do trabalhador pulverizado como 'personalidade bem integrada no grupo'" Cf. DEBORD, 1995. 33 BARTHES, 2007, pp. 95-97.
} 
A associação entre o mergulhador e o homem da organização tem como ponto de partida uma afirmação de Rosenquist sobre os trabalhadores engajados no projeto do F-111: "Um homem tem um contrato com a companhia que fabrica o bombardeiro, daí ele planeja [adquirir] o terceiro automóvel e [ter] o quinto filho, pois é um técnico e tem o trabalho [assegurado] pelos próximos anos". Fedders encontra nessas considerações um eco do que Whyte havia escrito a respeito do homem da organização, o qual existe "enquanto uma unidade da sociedade. Em si, ele é isolado e inexpressivo; torna-se útil só quando colabora com os outros, pois, ao sublimar-se no grupo, ajuda a produzir um todo que é maior do que a soma das partes". O mergulhador do artista encaixa-se nesse perfil: anônimo e substituível, explora as profundezas do mar para alguma corporação. Sua exalação em forma de cogumelo replica a forma da explosão atômica, dando a entender que ele participa da manufatura de produtos tanto benéficos quanto tóxicos. Sugerido pelo perfil rígido e fálico do bombardeiro, o homem-jato é dotado de um corpo tecnológico, trabalhando na conjunção do humano e da máquina. Do mesmo modo que o F-111, ele pertence ao circuito integrado do complexo militar-industrial.

Fedders delonga-se bem mais sobre a figura feminina, cujo rosto abrigaria uma hoste de mulheres: filha, dona de casa, símbolo sexual, consumidora e consumida. Na qualidade de filha, ela simboliza a família nuclear do segundo pós-guerra, engajada na reafirmação dos valores domésticos e dos papéis de gênero tradicionais. Típica representante da geração pós-beat, que não teme a ameaça nuclear, como lembra Rosenquist, a garota mantém-se alheia à presença do cogumelo, protegida por um capacete, que evoca uma campanha governamental do começo da década de 1950 intitulada "Abaixe-se e cubra-se”. Essa avaliação um tanto contraditória requer al guns esclarecimentos. O primeiro teste nuclear realizado pela União Soviética em 29 de agosto de 1949 acirra a tensão da Guerra Fria e leva a administração de Harry Truman a desenvolver um programa de defesa civil, que deveria ensinar a população a defender-se dos primeiros efeitos de uma explosão atômica. Em 1951, o diretor Anthony Rizzo realiza o filme Cover and duck (Abaixe-se e cubra-se), lançado em janeiro do ano seguinte. Tendo as crianças como público-alvo, o filme mistura animação e live action para ensinar métodos de proteção logo após o flash de uma explosão atômica. O recurso à animação tem diversas explicações: permite chamar a atenção das crianças e transmitir de maneira mais fácil a mensagem governamental por meio da Tartaruga Bert, que usava um capacete, mas era naturalmente protegida por sua carapaça quando da ocorrência de algum evento perigoso; é um meio barato para representar uma explosão atômica; torna a destruição menos real e mais abstra- 
ta. ${ }^{34}$ Ao longo do filme, Rizzo mostra diversas possibilidades de proteger-se da radiação atômica: esconder-se debaixo de mesas e carteiras, cobrindo a nuca e o rosto; deitar-se perto de paredes em espaços internos e de muros na rua; buscar abrigos públicos; proteger-se debaixo dos bancos do ônibus escolar; cobrir-se com toalhas e com jornais durante um piquenique... Bert torna-se um dos símbolos da campanha, pois ajudava a difundir sua mensagem central: ficar de pé e com o rosto desprotegido poderia provocar sérios problemas e, até mesmo, a morte.

Enquanto filha, a garota prefigura também o próprio futuro como dona de casa num ambiente cibernético, feito de utensílios domésticos, da flora disciplinada da paisagem suburbana e do próprio corpo feminino. Graças ao uso de recursos tecnológicos, a mulher torna-se uma "economista do lar", uma consumidora informada sobre os produtos mais avançados, que aliviavam as tarefas domésticas, deixando um maior tempo para cuidar das crianças. A dona de casa tecnológica desempenhava dois papéis fundamentais no âmbito da Guerra Fria: permitia afirmar a superioridade da economia doméstica norte-americana em relação à centralização soviética; ajudava a indústria a produzir bens de consumo e, por extensão, a criar postos de trabalho para os provedores de sexo masculino. Desobrigada do trabalho fora da esfera doméstica, dispunha de tempo para cuidar do corpo e de energia para oferecê-lo ao provedor, numa demonstração de como a tecnologia estava a serviço da reificação da mulher.

Outro papel atribuído à mulher é localizado no logotipo do avião sobreposto à nuvem atômica, que simula as promessas corporativas e a lealdade cega a determinadas marcas. Sua mensagem é clara: na qualidade de consumidor feminizado, a garota não deve preocupar-se com a guerra nuclear; deve, ao contrário, confiar cegamente nas forças armadas que garantem sua segurança contra possíveis incursões comunistas. Doutrinada pela publicidade e pelo governo, a garota é parte integral desse processo, pois usa o próprio corpo para vender produtos e ideologias, como salienta Rosenquist, ao caracterizá-la com os atributos de um símbolo sexual: cabelo loiro, olhar esquivo e lábios vermelhos. O fato de não ter um corpo diferencia, até certo ponto, a garota dos demais símbolos sexuais do artista; mas os cabelos e os lábios sugerem uma sexualidade latente, potencializada pelo secador, que pode ser visto como uterino por sua função precípua, e como fálico, por evocar um capacete.

A questão dos gêneros não se limita às figuras do mergul hador e da garota. Fedders localiza esferas femininas e masculinas nos diversos objetos que pontilham o painel de Rosenquist. O bolo 
vaginal, as lâmpadas uterinas, o secador de cabelo que evoca um ventre salientam a feminização da frente doméstica e o envolvimento da economista do lar na Guerra Fria. O pneu que assoma sobre o bolo pertence, ao contrário, à esfera do masculino. Como sublinha a autora, os anúncios publicitários divulgados pela revista Time ao longo dos anos de 1963 e 1964 associam o produto com o triunfo masculino nas 500 Milhas de Indianápolis, enquanto a mulher é apresentada como um ser impotente, que aguarda no acostamento a presença de um homem. Esta afirmação tem como base um anúncio da Goodyear, que mostra uma mulher apreensiva parada perto de um carro, observada pela filha debruçada na janela. O texto que acompanha a imagem tem um começo bem significativo: "Ela está parada. Desamparada. Um pneu murcho e ninguém à vista. Mas com o LifeGuard Safety Spare ela não teria que trocar o pneu". Na sequência, o texto louva as vantagens do duplo pneu, que permitiria alcançar o destino sem preocupar-se com uma eventual troca, mesmo depois da ocorrência de um furo, e termina com uma frase de efeito: "É quase tão bom quanto ter um homem por perto".

Publicado também na edição de Life de 26 de junho de 1964, o anúncio tem algumas variantes visuais divulgadas pela revista que merecem ser observadas. Em 17 de julho de 1964, um anúncio de duas páginas dá a ver um automóvel parado e uma jovem assustada. Uma variante dessa imagem, publicada em 18 de setembro de 1964, é mais sucinta, pois apresenta a mesma modelo assustada ao lado do automóvel. Em 21 de agosto de 1964 e 26 de fevereiro de 1965, os leitores de Life deparam-se com uma mulher elegantemente trajada, com o ar preocupado, inclinada na direção do veículo parado. Dirigido também à população negra, o anúncio é divulgado na revista Ebonyem março de 1965 e abril de 1966 e, embora traga a mesma mensagem, destaca-se por uma diferença significativa: a mulher, apesar de demonstrar certa dificuldade, está trocando o pneu sozinha.

Uma situação semelhante é encontrada num anúncio possivelmente posterior, cuja concepção é mais sofisticada. Articulada em dois espaços - a sequência fotográfica de uma mulher trocando um pneu e uma imagem poderosa do LifeGuard Safety Spare -, a peça publicitaria distribui a legenda entre eles. A primeira parte, com os dizeres “Quando não há um homem por perto...", está situada embaixo das nove fotografias da moça trocando o pneu; a frase "haverá Coodyear", completa o significado do anúncio e chama ainda mais a atenção para o produto. O texto que acompanha o restante do anúncio, é quase igual ao anterior, mas a frase final é alterada para "A segunda melhor coisa, quando não há um homem por perto". De maneira oblíqua, este último anúncio convidava a mulher a libertar-se da dependência masculina graças a um produto inteligente, que não exigia esforço físico ou habilidade manual. A figura masculina estava e não estava presente, já que o novo 
pneu não dependia mais de sua intervenção para ser trocado, deixando um maior espaço de decisão à mulher enquanto consumidora consciente e bem informada.

Fedders, que analisa a relação entre o bolo e o pneu a partir de um mesmo formato anular, sublinhando a existência de uma diferença de gênero entre o funil macio e vaginal do primeiro e a borracha dura do segundo, acredita que a presença deste no conjunto possa ter sido sugerida não apenas pela publicidade, mas também pelo happening Pátio (1962), em que Allan Kaprow havia dado ao pneu qualidades masculinas. A autora enfatiza o papel desempenhado por um desses objetos na obra de Kaprow: ele ameaça uma garota e provoca seu desaparecimento, "retirando-a da esfera pública da performance". O "happening encenado", isto é, baseado num roteiro, é bem mais complexo e seu significado é bastante hermético, envolvendo outros aspectos não analisados no artigo. A garota é, sem dúvida, coberta por uma montanha invertida de papel alcatroado, mas ela é agente ativa do acidente quando passa a desenrolar longas fitas de tecido branco colocadas ao lado da montanha maior na qual estava deitada. No momento em que a montanha menor começa a descer da lucerna na qual estava presa, ouvem-se os sons de uma sirene para neblina e de trombetas avisando do perigo. ${ }^{35}$ Fedders cita de relance um happening anterior, Quintal (1961), mas não discute suas implicações artísticas. Realizado no pátio da galeria Martha Jackson, inteiramente ocupado por pneus usados, o happening é concebido como uma crítica à visão corriqueira da arte, baseada na produção de objetos, e aos espaços convencionais de exposição. Evocando antes um ferro velho que uma galeria, Quintal adquire o caráter de obra de arte apenas no momento em que o público adentra o espaço e começa a interagir com os pneus - caminhando, sentando, deitando sobre eles, deslocando-os etc. -, a partir de parâmetros estabelecidos pelo artista. Esse último aspecto minimiza o tom de brincadeira que os participantes poderiam conferir às ações, já que o espaço abarrotado não poderia ser desmanchado por eles. ${ }^{36}$

Com base nesse conjunto de considerações, Fedders chega à conclusão de que Rosenquist desenvolve no painel "uma visão paranoica e, até mesmo sexista, dos corpos e da tecnologia", reforçando os papéis de gênero tradicionais. Nesse contexto, a garota

endossa alegremente a guerra atômica, a família nuclear, os aditivos alimentares ${ }^{37} \mathrm{e}$ as máquinas da indústria publicitária, apesar da ameaça potencial representada por produ-

\footnotetext{
35 BANDINI, s. d., p. 63.

36 SCHIMMEL, 2008, p. 17

37 A autora está se referindo às bandeirinhas colocadas em cima do bolo, que trazem os nomes dos produtos químicos presentes em sua composição.
} 
tos químicos e bombas. Seu corpo, envolvido na tecnologia, representa todas as mulheres e todos os americanos como drones estúpidos, manipulados facilmente e do mesmo modo pelas palavras lisonjeiras dos anunciantes e pelo governo.

Ao mesmo tempo que afirma que, na visão do artista, os papéis de gênero são fixos, a autora dá uma guinada brusca e admite que ele torna possível a subversão desse paradigma com a criação de dois ciborgues, frutos da fusão entre humano e mecânico. Antecipada pelo começo do artigo, no qual a garota e o mergulhador são definidos "dois humanos biônicos, enredados na maquinaria do consumismo da Guerra Fria", essa nova conclusão leva Fedders a escrever que os ciborgues de F-111 transcendem os papéis de gênero reforçados pela cultura norte-americana da segunda metade do século XX. No papel de piloto, a garota

sugere que qualquer corpo, fundido com a máquina, pode superar os gêneros, enquanto o Homem-Jato, na qualidade de mergulhador, não manifesta nenhuma característica de gênero [...]. Ambos são destituídos de corpos [...] Sem corpos, os ciborgues de Rosenquist são livres para colonizar o ciberespaço.

Essa conclusão surpreendente, que nega e ao mesmo tempo afirma a existência de uma visão crítica em F-111, nada mais faz do que corroborar a ambiguidade visual da obra, que cria aquela que Fedders denomina "uma nova ordem" por meio da fragmentação, da ampliação, da repetição e da justaposição de elementos das mais diversas proveniências e naturezas. Para afirmar a visão crítica de Rosenquist, a autora não precisaria recorrer à figura do ciborgue teorizada por Donna Haraway em 1985. "Imagem condensada" das transformações sociais e políticas que estavam ocorrendo no final do século XX graças ao binômio ciência-tecnologia, o ciborgue, enquanto híbrido de máquina e organismo, permite questionar a lógica dualista que rege a sociedade ocidental. As fronteiras entre humano e animal, organismo e máquina, físico e não físico deixam de ter importância na nova realidade, na qual a diferença tomou o lugar do paradigma identitário. Por meio do ciborgue, a bióloga e filósofa vislumbra um mundo sem gêneros, já que o dualismo homem/mulher deixou de ter importância diante do desmanche das dicotomias tradicionais. ${ }^{38}$

Já que Rosenquist não explora a problemática do pós-humano, teria sido bem mais produtivo debruçar-se sobre um livro como Mística feminina, no qual Friedan analisava o "problema sem nome" que atormentava a vida da maior parte das mulheres norte-americanas às voltas com um questionamento fundamental: sua vida resumia-se a ser dona de casa, mãe e esposa? Empurrada

38 HARAWAY, 2009. 
de volta para o lar depois do interregno da Segunda Guerra Mundial, durante o qual tinha desempenhado um papel econômico ativo, a mulher era incitada a lastimar "as infelizes neuróticas que desejavam ser poetisas, médicas ou presidentes". Em nome da "mística feminina" valorizava-se a mulher que "não desejava seguir carreira, obter educação mais aprofundada, lutar por direitos políticos e pela independência e oportunidades que as antigas feministas pleiteavam". ${ }^{39}$

Contando com um significativo apoio da imprensa, a realização das aspirações femininas tinha como eixo o casamento:

Milhões de mulheres moldavam sua vida à imagem daquelas bonitas fotos de esposa suburbana beijando o marido diante do janelão da casa, descarregando um carro cheio de crianças no pátio da escola e sorrindo ao passar o novo espalhador de cera no chão de uma cozinha impecável. [...] Seu sonho único era ser esposa e mãe perfeita. Sua mais alta ambição, ter cinco filhos e uma bonita casa. Sua única luta, conquistar e prender o marido. ${ }^{40}$

Se, no final da década de 1950, essa situação criava nas mulheres a sensação de serem prisioneiras, esse desconforto se tornava ainda mais agudo entre aquelas que haviam recebido uma educação superior. Qualidades associadas à imagem da "verdadeira mulher" (passividade sexual, domínio do homem, criação dos filhos e amor materno) eram incentivadas pelas revistas especializadas, as quais contribuíam também com estratégias publicitárias no trabalho de "esvaziamento da mente feminina". Na qualidade de dona de casa, a mulher tinha como função essencial "fazer compras para a família". O incentivo ao consumo leva Friedan a constatar que

a perpetuação e a expansão da mística feminina faz sentido (e dólares) quando se percebe que as mulheres, nos Estados Unidos, são as principais clientes em todos os setores. Alguém, algum dia, em algum lugar, deve ter descoberto que elas compram mais se foram mantidas no estado de anseio indefinido, de energia desperdiçada que caracteriza a dona de casa. ${ }^{41}$

Uma visita ao Instituto de Pesquisa Motivacional corrobora essa percepção, pois a autora ouve a seguinte ponderação de Ernst Dichter: "Corretamente manobradas [...], as donas de casa são capazes de obter senso de identidade, objetivos, criatividade, autorrealização e até satisfação sexual por meio da aquisição de objetos". Vítima "de um terrível dom, o poder aquisitivo", a mulher norte-americana vive num "confortável campo de concentração", de acordo com um conjunto de

\footnotetext{
39 FRIEDAN, 1971, pp. 17-18.

40 Ibid., p. 20.

41 lbid., pp. 59,180
} 
padrões que negam sua "personalidade adulta". Dependente, passiva e infantil, a mulher dedica-se a um trabalho monótono, que decreta "a morte lenta da mente e do espírito". ${ }^{42}$

A "mística feminina" denunciada por Friedan tem uma condensação emblemática em dois livros de Veronica Dengel: Personality unlimited: the beauty blue book (Beleza e personalidade: o livro azul da mulher), publicado em 1943, e Hold your man! (Agarre "seu" homem!), editado dois anos mais tarde. Guia prático "da saúde, beleza e para melhorar a personalidade”43, o primeiro livro traz conselhos sobre os cuidados que a mulher deveria ter com o próprio corpo, a começar por um regime controlado, que evitaria o excesso e a falta de peso, e pelo controle da "eliminação diária". Seguemse considerações sobre a menstruação ${ }^{44}$ e a menopausa ${ }^{45}$, a cerimônia do banho, os cuidados com a pele, a maquiagem, o cabelo, os olhos, as mãos, os pés e os exercícios de ginástica. Há também uma série de conselhos sobre a roupa, a voz e a maneira (correta) de falar, a etiqueta a ser seguida e a necessidade de adquirir novos conhecimentos na vida diária. A maneira correta de trajar é comparada pela autora com a composição de um quadro. Assim como o pintor, que "dedicou infinito carinho a cada ponto microscópico" para conseguir "a perfeição do todo", na mulher "verdadeiramente elegante, o que não podemos ver é tão importante como o que se vê. Sobre e sob deve vestir sua nova personalidade de forma que nenhuma nota soe desafinada, nenhum engano permitido". ${ }^{46} \mathrm{~A}$ ideia de que cabe à mulher ser impecável o tempo todo é resultado de uma soma de direitos e deveres. De maneira enfática, Dengel escreve:

É direito de toda mulher procurar ser bela, encantadora e admirada. É direito de toda

\footnotetext{
42 Ibid., pp. 182, 264-265.

43 DENGEL, 1944, s.p.

44 A quarta parte de Agarre "seu" homem! intitula-se "Cuidado!!! Esta parte está selada...", pois ela poderia ser retirada depois da leitura para evitar que um assunto de natureza privada pudesse chegar ao conhecimento do marido. Dengel ensina o uso correto do absorvente higiênico e aconselha sua troca a cada duas horas em caso de um fluxo abundante para garantir "segurança e frescura". Dá muita importância ao descarte, sugerindo queimar ou jogar o absorvente no vaso sanitário: "Jamais, jamais deixe um modess no cesto ou em qualquer outro receptáculo, onde seu marido possa encontrá-lo". Outros cuidados deveriam ser tomados para evitar que o marido ou qualquer outra pessoa descobrissem o período menstrual. Isso incluía a compra planejada de absorventes, que deveria ser feita por telefone e em grande quantidade para evitar uma aquisição de última hora na farmácia da esquina. Dengel não hesita em escrever: "Jamais peça ao seu marido que lhe faça tal compra, nem a faça você mesma, quando estiver acompanhada por ele./Não o arraste dentro da situação. Evite mencioná-la, se puder. Os homens não compreendem bem, nem se interessam pelo fenômeno". Outros aspectos "privados" são analisados nessa parte do livro como o asseio contra maus odores e as evacuações, que deveriam ocorrer sempre longe do marido para evitar destruir "a ilusão e o sonho que inspirou". Para que a mulher tivesse um ar refinado, a autora dá outros conselhos "preciosos": fumar de maneira graciosa, mas desistir do hábito se este desagradar o marido; "bebericar" socialmente (um cálice de xerez ou um coquetel) e evitar tomar cerveja em público, pois a mulher pareceria "pouco distinta, sentada num restaurante, com um copo diante de si"; não jogar nem praguejar... Esses conselhos - alguns dos quais serão retomados em Can I hold my beauty? (1946) - tinham como objetivo ocultar todos os vestígios da existência física da mulher para que o homem pudesse encontrar na esposa as qualidades da mãe. Cf. DENGEL, 1945, pp. 227-244; PERIL, 2002, p. 174.

45 A menopausa é apresentada de maneira positiva pela autora. Não representa o fim da juventude e o começo da velhice. Não significa o término da vida sexual ou do sex appeal. Não é um obstáculo à alegria de viver e à possibilidade de desenvolver-se intelectualmente. Pode, ao contrário, abrir novas perspectivas, já que o cuidado com os filhos deixou de ser um elemento primordial e a família alcançou um bom nível de prosperidade. Cf. DENGEL, 1944, p. 110.
}

46 DENCEL, 1944, p. 389. 
mulher aspirar a tanta beleza e encanto quanto possa obter. Mas a beleza não é apenas a perfeição do rosto e do corpo. [...] é uma combinação de aparência amável, refletindo uma saúde radiosa; de invulgar correção e limpeza da aparência, manifestação frequente da ordem mental; de facilidade e ritmo de movimentos, que exprimem uma serenidade interior nascida da pose e da autoconfiança.

Você poderá possuir também essa beleza. O material de que é formada dorme em você; tem apenas que despertá-lo.

A mulher é comparada a um diamante a ser lapidado em muitas facetas denominadas "saúde, vitalidade, beleza da pele e dos cabelos, um corpo esbelto, perfeição do make-up, saber vestir-se, modernidade na palestra e nas atitudes". Quem conseguisse polir todas essas facetas, teria uma "Personalidade Ilimitada". ${ }^{47}$

Essa tarefa hercúlea ganha reforço no livro seguinte, em que a autora estabelece um paralelo entre o aperfeiçoamento da sociedade e do mundo e os métodos empregados pela mulher para melhorar a unidade do lar e da família. Fascinante e sedutora graças aos cuidados com o corpo em termos alimentares, higiênicos e cosméticos, a mulher vive num palco - o lar-, no qual desempenha os papéis de produtor, diretor, empresário e estrela. O romance entre a estrela e o galã/marido constitui o ponto culminante do enredo. Na qualidade de palco, a casa divide-se em diversas cenas: cozinha, sala de jantar, sala de estar e dormitório. A cozinha deve estar "sempre em ordem e imaculadamente limpa"; a despensa, "sempre provida por regulares compras". Centro do lar, a sala de estar deve ser cuidadosamente planejada com "cores harmoniosas, cadeiras confortáveis, graciosos e úteis quebra-luzes, mesas e tapetes", pois nela "se evidencia a verdadeira expressão do seu êxito como esposa e mãe". O dormitório, que "foi a cena de iniciação da sua vida conjugal; [...] do princípio das vidas de seus filhos", deve continuar a ser "o cenário das sinceras demonstrações de suas mais fortes emoções". Por isso, ele deve estar em "especial harmonia" com a personalidade da mulher. Aconchegante e belo, o quarto de dormir deve possuir "uma atmosfera de romance", que tem seu ponto alto no leito, ao qual devem ser dispensados cuidados particulares. Ele deve ser "imaculadamente limpo", com lençóis e fronhas "tão finos quanto possível”, com cobertores combinando com o colorido da tapeçaria, da pele e dos cabelos da dona de casa, com colchas "graciosas e femininas"... Uma casa transforma-se em lar "quando a esposa e a mãe preenchem os requisitos de limpeza, atração, amizade e cooperação. A menos que haja felicidade, compreensão e união familiar, uma 
casa lindamente mobiliada será um lugar vazio". ${ }^{48}$

Este quadro de referências põe em xeque a ideia de Fedders de que Rosenquist se limita a endossar os papéis de gênero tradicionais em F-111. Em primeiro lugar, o painel é bem mais complexo do que a autora dá a entender. A imagem da garota integra um conjunto maior, no qual o artista demonstra a própria preocupação com um momento particular da história norte-americana, marcado por uma grande uniformidade, que ele resume na imagem de pessoas correndo em direção a "alguma luz ofuscante". Embora declare não ser contrário à máquina, o pintor concebe o painel como "um antídoto" contra os novos dispositivos que afetam a ética do ser humano e alerta a sociedade americana a não cair no conto de que a tecnologia resolverá todos os problemas. Essa preocupação fica evidente na dupla definição do bombardeiro. Por sua posição no painel, poderia ser visto como "um gigantesco bolo de aniversário, transportado por um caminhão para uma parada ou algo semeIhante -já foi usado dessa maneira -, mas foi desenvolvido para ser um terrível assassino". ${ }^{49}$

Embora Marcia Tucker afirme que muitos intérpretes de Rosenquist dão uma ênfase desproporcional ao significado simbólico dos objetos presentes em suas obras, alçando-os à categoria de coisas reais ${ }^{50}$, o próprio artista põe em xeque essa assertiva ao reiterar em diversas entrevistas os significados que embutiu em cada porção de F-111. Eminentemente crítica, a começar pelas dimensões que excedem as do avião real, a composição pode ser considerada uma tomada de posição contra uma situação política e social asfixiante e opressiva, marcada pela sombra de uma catástrofe iminente. Gene Swenson parece ter captado o conflito que agitava o artista quando abre a entrevista publicada na Partisan Review com as seguintes palavras: "A monumentalidade pode ser impossível numa época de obsoletismo embutido e o próprio artista tende a pensar o quadro mais como um suvenir do que como um monumento (e o próprio avião como um bolo de aniversário amargamente irônico)". ${ }^{51}$ O painel, no entanto, se impôs como um monumento, dominado por uma imagem central que ocupa quase toda a sua largura, no qual os diversos signos materiais associados a ela criam uma visão complexa dos Estados Unidos na primeira metade da década de 1960.

Swenson está, sem dúvida, certo quando apresenta Rosenquist como um artista portador de "uma atitude filosófica, que é totalmente consciente em termos sociais" ${ }^{22}$ Isso é demonstrado de sobejo por suas obras anteriores e posteriores a F-111, nas quais coloca sob escrutínio alguns dos

\footnotetext{
48 DENGEL, 1945, pp. 12, 179, 182, 186-187.

49 SWENSON, 1965, pp. 590, 598, 600-601.

50 TUCKER, 1972, p. 14.

51 SWENSON, 1965, p. 589

52 SWENSON, 1966, p. 38.
} 
aspectos centrais da sociedade de seu país: espetáculo da mercadoria; onipresença da publicidade, que se infiltra até mesmo na política; obsessão pelo novo e pelo reluzente; exploração do apelo sexual para vender todo tipo de produto; culto do automóvel e da tecnologia. Com suas composições repletas de mistério, de enigmas, de incongruências e contradições visuais, de mudanças de escala abruptas e de um processo de fragmentação intenso, o artista visa criar um estado de desconforto no espectador para levá-lo a questionar a realidade criada e gerenciada pelos meios de comunicação de massa. No caso de F-111, esse questionamento atinge uma dimensão física, pois alguns painéis de aço destituídos de imagens funcionam como espelhos, envolvendo o observador diretamente na cena representada. Em termos gerais, porém, o posicionamento do público é mental, já que Rosenquist o convida a confrontar sua percepção pessoal com os enigmas presentes nas telas.

Um quadro produzido durante a gestação de F-111 pode ser considerado paradigmático desse processo. Enigmático desde o título, Voluntário (1964) estrutura-se, em parte, como um quebracabeça incompleto. Uma máquina de lavar roupa apresentada parcialmente, um corpo masculino destituído de cabeça e um enorme sorvete partilham o espaço com um grande cinto. Sobre o fundo vermelho vivo, que toma conta da maior parte da composição, está estampada a palma de uma mão em tom amarelo e em duas gradações de azul. A presença de dois signos da cultura material norte -americana - um eletrodoméstico e um alimento - inscreve o quadro no âmbito da visão crítica que o artista tem do próprio país e de seus hábitos de consumo. O homem decapitado e, logo, privado de identidade, corresponde ao enigma buscado pelo pintor. Trata-se de um "homem da organização"? Ou de um voluntário para o serviço militar? A pose rígida, que denota obediência, favorece as duas interpretações, já que ambas remetem a uma realidade inelutável: o "complexo militar-industrial", denunciado em F-111. A peça que falta no quebra-cabeça e a palma da mão poderiam fazer pensar numa estrutura incompleta e aberta a diferentes possibilidades e na presença direta do artista, que deixa uma marca de sua intervenção numa realidade complexa e contraditória. Uma observação manuscrita num estudo preparatório parece fornecer uma pista para a interpretação da peça faltante no quebra-cabeça, já que ela cria uma associação entre "puzzle" e "puzzled": "O voluntário, que está perplexo, não sabe o que fazer, a não ser desejar".

Para e exposição Rosenquist, apresentada na galeria Leo Castelli entre 17 de abril e 13 de maio de 1965, o artista realiza um cartaz concebido como uma síntese visual de F-111. Dominada por um gigantesco secador de cabelos, a peça compõe-se de fragmentos isolados, que se fundem num conjunto bastante paradoxal, pois não parecem manter qualquer ligação entre si. O rosto sorridente da menina é parcialmente atravessado por uma zona vermelha, constituída pela porção inferior do 
papel de parede sobre o qual estão posicionados um ovo inteiro, outro quebrado e uma lâmpada. Sobre a cabeça da menina paira uma estrela extravagante associada a duas listras; pelo colorido, o conjunto remete à bandeira norte-americana. Ainda mais enigmática que o painel, a composição de 1965 parece apontar para uma relação direta entre a figura feminina e signos de consumo, cuja proliferação na vida norte-americana levou Marcia Tucker a detectar neles a presença de "uma espécie de conteúdo cultural". ${ }^{33}$ Não se trata, no entanto, de uma confirmação passiva do papel da mulher na sociedade e, sim, de uma visão crítica do "modo de vida americano", dentro do qual a esposa-mãe desempenhava a função primordial de consumidora e, logo, de incentivadora do progresso econômico do país. No discurso proferido por Adlai Stevenson no Smith College (1955), a participação política da mulher na vida do país é reconduzida justamente a seu papel de esposa e mãe. O representante do liberalismo democrático afirma sem rodeios que a tarefa política da mulher consistia em "criar no seu lar um ideal de vida e liberdade". Essa missão podia ser realizada "na sala, com uma criança ao colo, ou na cozinha, empunhando um abridor de latas. [...] Creio que no humilde papel de dona de casa há muita coisa a fazer em relação à nossa crise. Não Ihes desejo vocação melhor que esta". ${ }^{54}$

Obra complexa e enigmática, F-111 confronta o observador com um quebra-cabeça no qual é necessário encaixar fragmentos aparentemente abstratos para que eles adquiram uma significação precisa por sua inserção num conjunto maior. De acordo com uma declaração do artista não compreendida de todo por Fedders, a menina representa "a forma feminina no quadro" e sua presença é um antídoto à abstração. O que Rosenquist quis dizer é que, se naquela porção do painel não houvesse a figura da menina, não seria possível captar a mensagem central da composição: a de que o "modo de vida americano" e a expansão imperialista dos Estados Unidos constituíam um todo indissociável, pouco importando os danos que este acarretaria a outras populações. O fato de o pintor explorar imagens provenientes das décadas de 1940-1950 e dos primeiros anos da de 1960 reforça o viés crítico do painel, já que é justamente naquele período que se consolida o "modo de vida americano". A guerra do Vietnã, nesse contexto, é um episódio entre outros, pois o poder de destruição bélica estadunidense já havia sido demonstrado de sobejo em episódios anteriores. O F-111 estava ainda sendo testado no momento em que o pintor realiza seu painel, mas não era necessário aguardar sua construção final, pois se sabia de antemão seu papel na defesa acirrada dos interesses nacionais, confundidos de propósito com a salvaguarda da democracia e da liberdade. 


\section{REFERÊNCIAS BIBLIOGRÁFICAS}

BANDINI, Mirella. "Allan Kaprow". Disponível em: <www.artslab.com/data/img/pdf/016_60-67.pdf>. Acesso em: 24 out. 2019.

BARTHES, Roland. Mitologias; trad. Rita Buongermino et al. Rio de Janeiro: Difel, 2007, pp. 95-97.

BLAUT, Julia. "James Rosenquist: collage and the painting of modern life". In: HOPPS, Walter \& BANCROFT, Sarah (org.). James Rosenquist: a retrospective. New York: Guggenheim Museum, 2003, pp. 16-45.

COLLINS, Bradford R. Pop art. London: Phaidon Press, 2012.

DEBORD, Guy. La sociedad del espectáculo. Buenos Aires: La Marca, 1995.

DENGEL, Veronica. Agarre "seu" homem!; trad. Susana Flag. Rio de Janeiro: Edições Cruzeiro, 1945.

Beleza e personalidade: o livro azul da mulher; trad. Elza Marzullo. Rio de Janeiro: Empresa Gráfica "O Cruzeiro", 1944.

FEDDERS, Kristin U. "Jet-man meets cover girl at the F-111: gender and technology in James Rosenquist's F-111" (out. 2006). Disponível em:<https://www.colorado.edu/gendersarchive1998-2013/2006/10/01/jet-man-mets-cover-girl-atthe-f-111-gender-and-techonology-in-james-rosenquists-f-111>. Acesso em: 15 out. 2019.

FERRIER, Jean-Louis. Picasso Cuernica: anatomie d'un chef-d'oeuvre. Paris: Denöel/Gonthier, 1977.

FRIEDAN, Betty. Mística feminina; trad. Áurea B. Weissenberg. Petrópolis: Vozes, 1971.

GELDZAHLER, Henry. "James Rosenquist's F-111". The Metropolitan Museum of Art Bulletin, New York, v. 26, n. 7, mar. 1968, pp. 277-281.

"Ceneral Dynamics F-111 Aardvark". Disponível em: <https:/en.wikipedia.org/wiki/General_Dynamics_F-111_Aardvark>. Acesso em: 31 jan. 2019.

HANDLER, Beth. "Rosenquist. F-111. 1964-65". In: UMLAND, Ann (org.). Pop art: selections from the Museum of Modern Art. New York: Museum of Modern Art, 1998, pp. 90-91.

HARAWAY, Donna ]. "Manifesto ciborgue. Ciência, tecnologia, feminismo-socialista no final do século XX". In: TADEU, Tomaz (org.). Antropologia do ciborgue: as vertigens do pós-humano; trad. Tomaz Tadeu. Belo Horizonte: Autêntica, 2009, pp. 33-118.

HOWAT, John K. "Washington crossing the Delaware". The Metropolitan Museum of Art Bulletin, New York, v. 26, n. 7 , mar. 1968, pp. 289-299.

KRAMER, Hilton. "Art: A new hangar for Rosenquist's jet-pop 'F-111'. In: MADOFF, Steven Henry (org.). Pop art: a critical history. Berkeley/Los Angeles/London: University of California Press, 1997, pp. 253-254.

LOBEL, Michael. James Rosenquist: pop art, politics and history in the 1960s. Berkeley/Los Angeles /London: University of California Press, 2009.

"Operation Crossroads". Disponível em: <https://en.wikipedia.org/wiki/Operation_Crossroads>. Acesso em: 25 jan. 2019.

PERIL, Lynn. Pink think: becoming a woman in many uneasy lessons. New York: W. W. Norton and Company, 2002.

ROSENQUIST, James. Painting below zero: notes on a life in art. New York: Albert A. Knopf, 2009.

S. A. "Duck and cover. - The infamous Cold War civil defense film". Disponível em: <www.historyisnowmagazine.com/ blog/2014/3/28/duck-and-cover-the-infamous-cold-war-civil-defense-film\#.Xaoo.W9Qr>. Acesso em: 18 out. 2019.

SCHIMMEL, Paul. "'Only memory can carry it into the future': Kaprow's development from the action-collages to the happenings". In: MEYER-HERMANN, Eva; PERCHUK, Andrew; ROSENTHAL, Stephanie (org.). Allan Kaprow: art as life. Los Angeles: Cetty Research Institute, 2008, pp. 8-18.

SCULL, Robert C. "Re the F-111: a collector's note". The Metropolitan Museum of Art Bulletin, New York, v. 26, n. 7, mar. 1968, pp. 282-283. 
SOOKE, Alastair. Pop art: a colorful history. New York: Viking Press, 2015.

SWENSON, G. R. "The F-111. An interview with James Rosenquist". Partisan Review, New York, v. 32, n. 4, outono 1965, pp. 589-601.

The other tradition. Philadelphia: The Institute of Contemporary Art/University of Pennsylvania, 1966.

TILLIM, Sidney. "Rosenquist at the Met: avant-garde or red guard?" In: MADOFF, Steven Henry (org.). Pop art: a critical history. Berkeley/Los Angeles/London: University of California Press, 1997, pp. 258-262.

TUCKER, Marcia. James Rosenquist. New York: Whitney Museum of American Art, 1972.

"USS Intrepid (V-11)". Disponível em:<https://en.wikipedia.org/wiki/USS_Intrepid_(V-11)>. Acesso em: 31 jan. 2019. 